\title{
FABRICAÇÃO DE UM DISPOSTIVO DE PROTEÇÃO PARA DEFICIENTES AUDITIVOS
}

\author{
Gabriel Mendes de Souza, (UFCG), gabrielmendes384@gmail.com \\ Natália Albuquerque dos Santos, (UFCG), natalia.dealbuquerque@ hotmail.com
}

\section{Resumo}

Dispositivos e equipamentos que remetem a segurança oferecem conforto e praticidade estão diretamente relacionados às questões de segurança do trabalho e à interseção dos alunos portadores de necessidades especiais no regime regular de ensino. Diante disso, torna-se necessário desenvolver possibilidade cuja finalidade seja simplificar essa inclusão social. Logo, este estudo teve como propósito a elaboração de um produto de proteção destinado a deficientes auditivos com o intuito de que eles possam ser inclusos à sociedade em que vivem não somente em ambiente acadêmico como também empresarial. Portanto, de acordo com o que foi pesquisado e avaliado, é notória a eficácia do produto finalizado nos âmbitos propícios à inclusão dos surdos para que eles sintam "conforto" quando tentarem se comunicar com os outros indivíduos dentro de ambientes fechados.

Palavras-chave: Deficiente auditivo. Dispositivo de proteção. Inclusão social.

\section{Introdução}

O uso de dispositivos e equipamentos que remetem a segurança oferece conforto e praticidade está diretamente relacionado as questões de segurança do trabalho, e com a interseção dos alunos portadores de necessidades especiais no regime regular de ensino, torna-se necessário desenvolver possibilidade que possa simplificar essa inclusão.

Segundo Cassiano (2017), o uso da língua de sinais está sendo reconhecido como caminho necessário para uma efetiva mudança nas condições oferecidas pela escola no atendimento escolar dos alunos portadores de deficiência auditiva, não podendo ser ignorado pela escola no processo ensino e aprendizagem do educando, se constituindo em um alicerce para sua comunicação. Baseando-se no princípio "igualdade de oportunidades" e "educação para todos". 
Muito se questiona sobre as responsabilidades do governo e cidadãos em de fato combater a exclusão de qualquer indivíduo no sistema educacional de ensino, e com a oficialização da LEI 10.436 em abril de 2002, que reconhece a língua de sinais e que integra os alunos portadores de deficiência auditiva no sistema de ensino, tornou -se fundamental desenvolver por meio de tecnologias que possam promover de fato essa integração e excluir qualquer má desconforto que possa existir.

Destarte, o presente estudo e trabalho teve como proposta desenvolver um dispositivo que pudesse ser capaz de se adaptar ao máximo ao ambiente inserido (sala dos professores), local esse utilizado para atendimentos extra curriculares com a finalidade de que as pessoas com deficiência auditiva possam ser inclusas à sociedade em que vivem em ambiente acadêmico e empresarial.

\section{Referencial Teórico}

\subsection{Trajetória do Surdo na História}

Durante a idade antiga (escrita a 476 D.C.), na Grécia e Roma, os surdos eram vistos como amaldiçoados ou castigados e, consequentemente, abandonados por serem considerados inválidos e incômodos à sociedade e por isso eram mortos, sendo lançados em rios ou jogados de abismos, e os surdos que sobreviviam viviam como escravos ( STROBEL, 2009).

Na Idade moderna (1453 - 1789), é relatado alguns casos de surdos que aprenderam língua de sinais para se comunicar, que é considerado um grande avanço para o povo surdo, pois começaram a ser vistos como indivíduos que podem sim ser receber educação e que podem se comunicar (STROBEL, 2009).

\subsection{Acessibilidade Comunicacional para Surdos}

É válido salientar que a nova definição de deficiência é responsável por orientar políticas públicas. Entretanto, ela não garante a total aplicação dessas medidas. Portanto, as instituições sociais e os responsáveis por divulgar e veicular essas informações são os responsáveis por tal situação com o intuito de haver quebras de preconceitos que ainda existem na sociedade em que os surdos estão inseridos (BROETO,2015).

Embora haja um reconhecimento crescente na importância da acessibilidade, nota-se que este tema ainda está centrado sobretudo em questões arquitetônicas, deixando de lado outros tipos de barreiras enfrentadas pelas pessoas com deficiência, como a comunicacional, que é 
responsável por impedir o acesso à plena comunicação interpessoal, escrita e virtual. Diante disso, como consequência desse ato, os indivíduos não têm acesso à informação e ao conhecimento.Com isso, é percebido que ainda há muito para ser feito em relação à direção da conquista da acessibilidade na comunicação, uma vez que garantir acessibilidade comunicacional está voltado ao direito à participação das pessoas com deficiência na vida pública do país (GRACIOLA,2014).

\subsection{Inclusão Social dos Surdos}

Em relação à inclusão social, existe uma lei chamada de a Lei $n^{\circ}$ 13.146, de 6 de julho do ano de 2015 que criou a lei Brasileira de Inclusão da pessoa com deficiência .No artigo 84º , essa lei informa que o deficiente auditivo tem o direito da capacidade legal dele com a sociedade em que vive, tendo condições de igualdade com as demais pessoas, ou seja ,os surdos devem ter direitos e deveres como qualquer um cidadão normal, como, por exemplo, dessa forma, a moradia, a educação, a saúde, o trabalho, a acessibilidade e a igualdade (RIBEIRO,2017).

Conforme uma organização da sociedade civil chamada de Nossa Causa, A inclusão social de surdos no Brasil está sendo cada vez mais complicada, embora se tenha avançado com a criação da segunda língua brasileira, que é a libras, uma vez que o mercado de trabalho, por exemplo, não contratam, na maioria das vezes, deficientes auditivos, são poucos os empresários que contratam esse público para trabalhar, o que se tem custo por parte das empresas a adaptarem o ambiente de trabalho ao surdo, sendo o motivo da não contratação. Além do mais, é importante salientar que existem surdos que acabam tendo salas separadas de outros alunos sem a deficiência auditiva, sendo afastados do restante dos outros estudantes no ambiente educativo.

\subsection{Tecnologia Assistiva}

“As Tecnologias Assistivas (TAs) potencializam a acessibilidade comunicacional, possibilitando criar conteúdos digitais com múltiplas linguagens e mídias a serem utilizadas como CAA, Comunicação Alternativa e Aumentativa." (DA COSTA,2017).

A Tecnologia assistiva pode ser vista como uma mediação instrumental voltada aos processos que são responsáveis por favorecer, compensar, auxiliar, e/ou potencializar as funções pessoais danificadas pela deficiência entrelaçada às funções motoras, visuais, auditivas e comunicativas. Desse modo, é importante perceber que as estratégias pedagógicas e educacionais são as responsáveis por disponibilizar o conhecimento ao aluno portador da determinada deficiência, e não a tecnologia assistiva, a qual tem como função ser apenas o instrumento de mediação que 
acaba facilitando para que o entendimento chegue ao estudante deficiente ( GALVÃO FILHO,2009).

É importante analisar que existem diversos tipos de softwares de comunicação, que podem ser utilizados por pessoa com comprometimento na fala. No caso de surdos usuários de Libras, o funcionamento de tais softwares se dá através da tradução do texto escrito para Libras, o que facilita o acesso às informações disponibilizadas aos usuários. O Hand Talk, ProDeaf, Rybená são exemplos deste tipo de software, podendo ser utilizados em páginas web e em Ambientes Virtuais de Aprendizagem (AVA), favorecendo ao surdo o acesso a diversos tipos de informações veiculadas nesses ambientes. Além disso, com esse propósito, existe o Vlibras que traduz conteúdos de sites, áudios e textos para Libras e pode ser instalado em computadores, navegadores e celulares(SOUZA RIBEIRO,2018).

\subsection{Arduino e sua Importância}

De acordo com o site do Arduino, é entendido que o Arduino pode ser considerado como uma plataforma eletrônica open-source quando há facilidade em relação ao uso do hardware e software com o intuito de ser utilizada para qualquer pesquisador realizar projetos. Nisso, é válido salientar que o Arduino board é responsável por ler variáveis de entrada, como, por exemplo, uma luz num sensor, um dedo no botão, entre outras, transformando-as, consequentemente numa variável de saída ao ter ativado um motor ou ligando uma luz. Isso ocorre por o programador fornecer instruções de funcionamento ao microcontrolador do quadro do aplicativo em questão. Para que isso seja feito, é necessário o uso da linguagem de programação de Arduino baseado na fiação, assim como o uso do software com base no processamento é indispensável.

O Arduino pode ser entendido como hardware e software ao estar aberto ao uso e contribuindo à sociedade. Ele também é uma ferramenta de open-source e de fácil aquisição. Além do mais, é válido salientar que existem fóruns na Internet que podem oferecer suporte aos usuários e àqueles que pretendem realizar projetos, bem como o compartilhamento de ideias e projetos com outros projetistas (ARAÚJO,2012).

\subsection{Higiene e Segurança do Trabalho}

"A higiene e segurança do trabalho estão relacionadas a um conjunto de leis, normas, procedimentos técnicos e educacionais que visam à proteção de integridade física e mental do 
trabalhador, preservando-o dos riscos à saúde, inerentes as tarefas do cargo e ao ambiente onde são executadas." (EGGERS,2005).

A higiene e segurança do trabalho ,em parceria com outras áreas afins - a ergonomia, saúde ocupacional e saúde do trabalhador-, deve não somente identificar os fatores de riscos responsáveis por ocasionar acidentes e doenças ocupacionais, bem como fazer avaliações referente aos efeitos desses riscos na saúde do operário e ,consequentemente, colocar medidas de intervenção técnica no ambiente de trabalho em que o funcionário está inserido ( MATTOS,2011).

\subsection{Equipamentos de Proteção}

É entendido pelo termo equipamento de proteção individual (EPI), todo dispositivo ou produto que deve ser usado de forma individual pelo próprio trabalhador à sua proteção de riscos suscetíveis que podem colocar em perigo tanto a segurança quanto a saúde no trabalho (NR$6,2011)$

Equipamento de proteção coletiva pode ser entendido como um sistema integrado que possui dispositivos responsáveis por proteger mais de um indivíduo no ambiente trabalhista, isto é, são dispositivos usados para a proteção de mais de um indivíduo em ambiente laboral (OLIVEIRA,2017).

\subsection{Prototipagem}

A prototipagem é considerada como uma ferramenta que pode ser utilizada com a finalidade de melhorar a comunicação e que seus benefícios derivam desse valor básico que são oferecidos por protótipos de todos os tipos. Nisso, um protótipo é responsável por mostrar um design de um produto novo a ser feito e a realização de decisão no processo, isto é, o protótipo tem a função de simples e rapidamente de comunicar o novo design do produto (GRIMM,2004).

Protótipo significa a primeira forma cuja derivação é grega (GRIMM,2004). Logo, essa definição genérica diz respeito à produção prévia de um determinado produto, a fim de evitar que erros sejam ocorridos. Dessa forma, ao realizar uma prévia em relação à produção do produto, ele pode não ter defeitos estéticos e funcionais, uma vez que o protótipo foi feito e ele não apresentou quaisquer defeitos. 


\section{Metodologia}

Foi-se feita uma entrevista na data de 17 de outubro de 2019 com a professora de libras da Universidade Federal de Campina Grande do Centro de Desenvolvimento Sustentável do Semiárido. Nessa pesquisa, Denise Maria Duarte Coutinho, nome da docente, informou que almejaria de ter um equipamento de proteção para pessoas com deficiência auditiva no intuito de que estas pudessem se comunicar com o professor sem ter o contato visual em salas fechadas cujas portas não apresentassem vidro, porém ela não tinha conhecimentos da elaboração do equipamento. A pesquisa contou com aparelhos celulares com a finalidade de registro de gravação. Posteriormente, com a finalidade de conseguir conhecimentos em relação à elaboração do equipamento, foi-se necessário entrevistar o docente de automação cujo nome é Rômulo da mesma instituição de ensino em questão.

Com isso, foi-se preciso adquirir os principais materiais como o kit completo do Arduino UNO, o filamento PLA da impressão e campainha sem fio por meio de compras em sites, enquanto os demais materiais usados na elaboração do equipamento são de autoria do laboratório de automação da Universidade Federal de Campina Grande do Campus de Sumé. Os materiais utilizados na elaboração do equipamento são um Arduino UNO, o filamento PLA branco Basic de 500g,uma campainha sem fio de funcionamento na base de pilha com o modelo da force line, duas placas Fenolite perfuradas de dimensão 9x15 cm, três botões Pushbutton com capa colorida de cores vermelha, amarela e verde, seis LEDS com dois de cor amarela, dois de cor vermelha e dois de cor verde, uma protoboard, sete jumpers, 9 resistores cuja resistência é de 220 ohms e dois fios pequenos, o ferro de solda, o estânio e a impressora 3D.

Em primeiro plano, foi-se realizado o protótipo e depois aprimorado usando a placa do Arduino Uno em parceria com a protoboard, os seis LEDS, os três botões coloridos, os sete jumpers e os nove resistores de $220 \mathrm{ohms}$. Nisso, é necessário ressaltar que se foi feita a programação no Software do Arduino na linguagem $\mathrm{C}++$ de acordo com o apêndice A e em seguida realizada a fiação com todos esses equipamentos na protoboard. Nesse contexto, foi-se necessário adquirir conhecimentos da realização das tarefas tanto da parte da Programação quanto da eletrônica na internet ao ver vídeos aulas, assim como foi-se necessário entrevistar o docente Rômulo, professor de automação da própria universidade em questão, no que tange ao funcionamento do Arduino como um todo tanto da parte da programação quanto da fiação.

Em segundo plano, após a realização do protótipo, foi-se necessário a realização do produto. Nisso, foi-se utilizado as duas placas perfuradas fenolite de dimensão 9x15 cm para que numa 
delas seja colocada a placa do Arduino UNO junto com todos os equipamentos do protótipo, ou seja, os três LEDS, seis jumpers, que são os fios de interligação da placa com as portas do Arduino, e os três botões com capa colorida com as cores de vermelho, amarelo e verde, enquanto na outra placa perfurada fenolite, foram utilizados apenas três LEDS de coloração vermelha, amarela e verde. Diante disso, é importante salientar que após a fiação está completa nas duas placas, foi-se necessário a realização da soldagem mediante a colocação do estânio com o ferro de estânio.

Em quarto plano, foi-se necessário a realização do enclausuramento das duas placas mediante a impressora 3D ao usar a matéria prima para a impressão, isto é, o filamento PLA branco Basic de 500 g. Destarte, tem- se o produto com duas caixas interligadas com fiação e a campainha para fazer parte do sistema.

Em seguida, para a fabricação do produto de proteção, a tabela 1 mostra os custos dos materiais utilizados:

Tabela 1- Custos da fabricação do equipamento de proteção para pessoas com deficiência auditiva

\begin{tabular}{|c|c|c|}
\hline Materiais comprados & Quantidades & Preço unitário (\$) \\
\hline Arduino Uno & 1 & 160,00 \\
\hline Campainha sem fio & 1 & 57,60 \\
\hline $\begin{array}{c}\text { Filamento PLA Branco } \\
\text { Basic de 500 g }\end{array}$ & 1 & $7,90,00$ \\
\hline Placas Perfuradas Fenolite & 2 & 0,90 \\
\hline Botão Pushbutton Amarelo & 1 & 0,90 \\
\hline Botão Pushbutton Verde & 1 & 0,90 \\
\hline Botão Pushbutton Vermelho & 1 & 6,00 \\
\hline Papel Adesivo & 1 & 338,10 \\
\hline Total & 9 & \\
\hline
\end{tabular}

Fonte: Autoria Própria (2019)

\section{Resultados}

O equipamento de proteção para deficientes auditivos é composto pelo produto final que consiste em dois suportes, um que está acoplado o Arduino chamado de suporte 1 junto com os demais equipamentos, isto é, os três botões Pushbutton de cor vermelha, verde e amarela e os 
três leds com essas mesmas cores respectivamente, e que esse determinado suporte 1 deve estar dentro da sala do professor, especialmente encima do birô. O suporte 2 deve estar no lado de fora da sala sobretudo na porta e está interligado ao primeiro suporte mediante a fiação com o intuito de haver a comunicação entre eles. Para fazer parte do funcionamento do sistema, temse a campainha sem fio, a qual deve estar localizada dentro da sala do docente próximo ao suporte 1, enquanto o botão dela deve se localizar externamente à sala, ou seja, na porta próximo ao suporte 2 em parceria com uma legenda (figura 2) feita em papel adesivo colado próximo a não somente ao suporte 2, como também ao botão da campainha. Essa legenda explica como funciona o produto de proteção.

O funcionamento do sistema em questão ocorre quando a pessoa com deficiência auditiva clica no botão da campainha que está externamente à sala de aula. Nisso, consequentemente, o professor é informado mediante a emissão do som do determinado equipamento oriundo do clique do botão da determinada campainha pelo deficiente auditivo. Dessa forma, ele responde a pessoa com deficiência auditiva por meio do clique de um dos três botões. Por exemplo, o botão vermelho informa que está ocupado e volte mais tarde, o amarelo informa que aguarde um instante e, por último, o verde, pode entrar. A partir do momento em que um desses três botões é acionado no suporte 1 que deve estar conectado a uma fonte de qualquer bateria ( fonte de energia) via cabo USB, é emitido um dos três LEDS no suporte 2 assim como do suporte 1 com o intuito de responder a pessoa com deficiência auditiva se ela pode ou não ter autorização de entrada à sala. Nisso, é válido salientar que os LEDS do suporte 1 existem no intuito de fazer com que o professor esteja ciente de que o LED correto foi acionado, assim ele deve clicar duas vezes em um dos botões: um clique para acender o LED e outro com a finalidade de desligá-lo.

Em seguida, a figura 1 mostra o sistema como um todo em relação ao seu funcionamento: 
Figura 1- sistema do produto de proteção para surdos

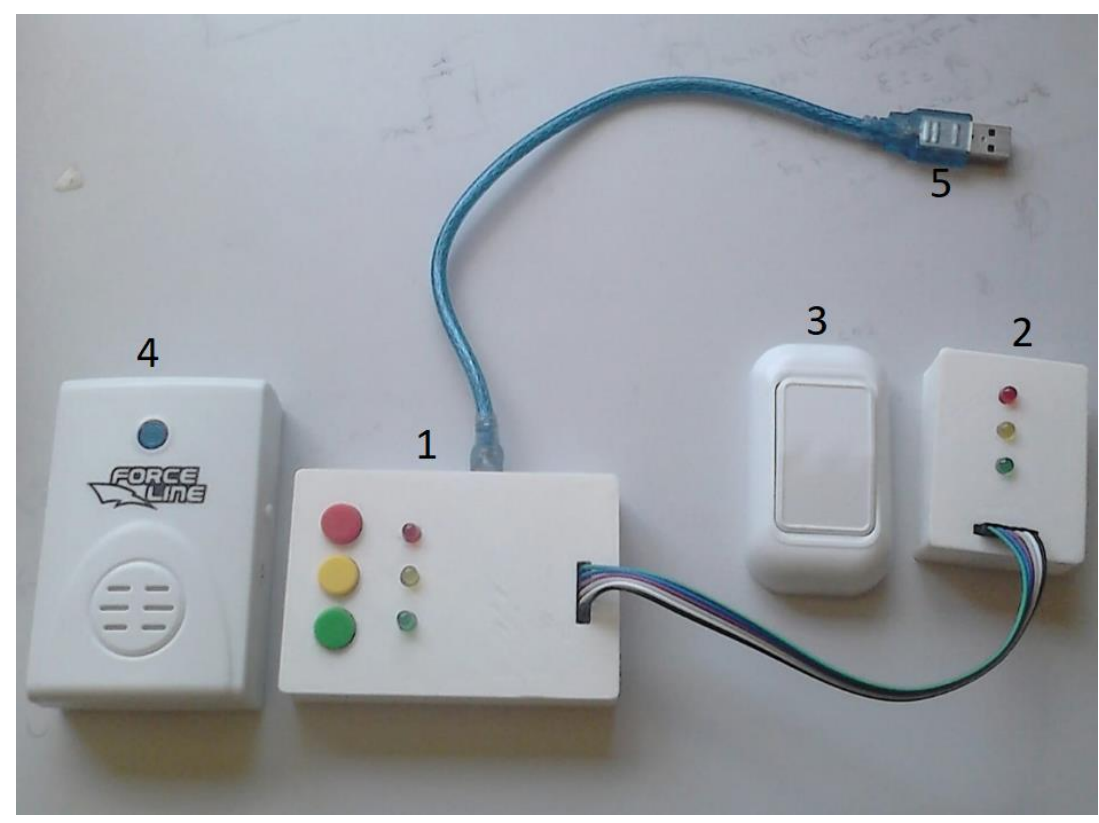

Fonte: Autoria Própria (2019)

O número 1 representa o suporte 1 que é responsável por responder o deficiente auditivo; o número 2 é o suporte 2,o qual é responsável por informar ao surdo em relação à autorização de entrada à sala do docente; o número 3 é o botão da campainha na qual a pessoa com deficiência auditiva irá clicar com a finalidade de informar ao professor que deseja permissão para entrar na determinada sala; o número 4 é campainha a qual está próxima ao suporte 1 no lado interno da sala especialmente encima do birô e tendo como função emitir o som para que o docente esteja ciente de que se tem uma pessoa auditiva a espera de permissão de entrada; e, por último, tem-se o número 5,o cabo USB, que deve ser conectado a qualquer fonte de energia, como, por exemplo, uma bateria, ou até mesmo o próprio computador do professor ,com o intuito de fornecer energia para que o sistema seja ligado e funcione.

A seguir, a figura 2 mostra a legenda que deve ser usada para compor o sistema, a qual está no lado externo da sala do professor em parceria com o suporte 2 e o botão da campainha. 
Figura 2- Legenda do produto de proteção para deficientes auditivos
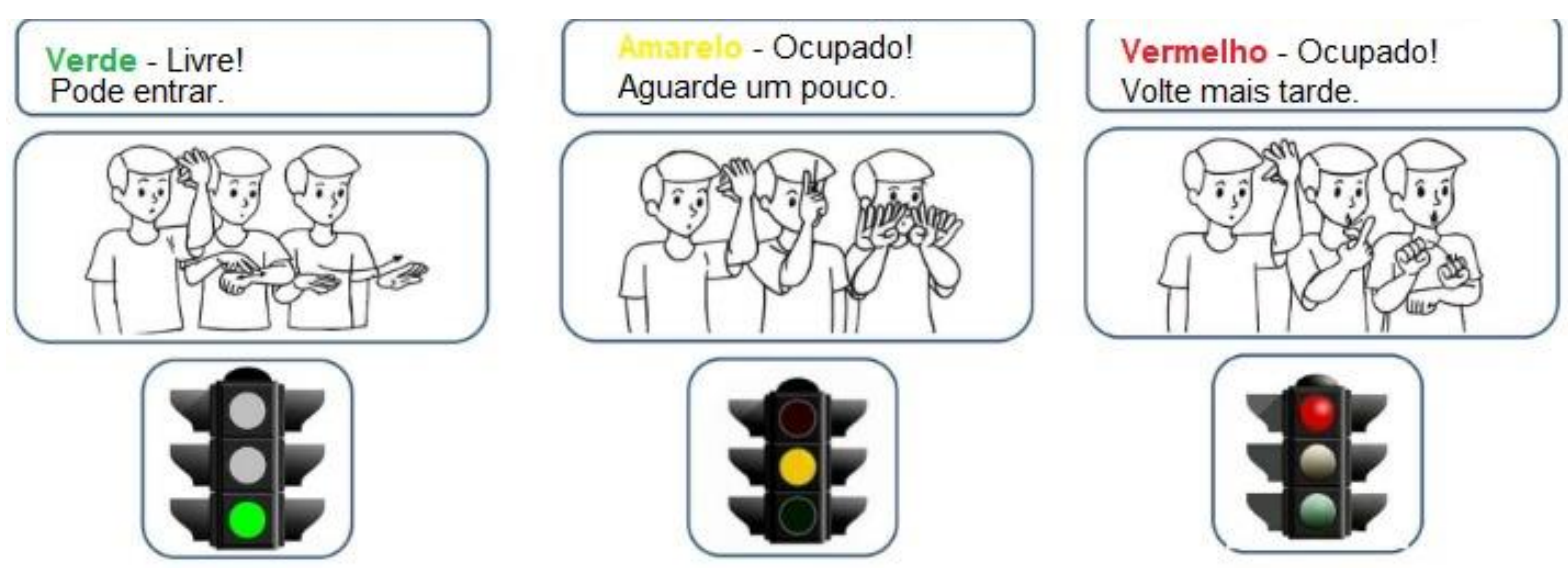

Fonte: Autoria Própria (2019)

Tal imagem tem a função de explicar ao surdo o funcionamento do produto de proteção ao explicar o significado de cada cor emitida pelo suporte 2: a cor vermelha avisa para voltar mais tarde por o professor estar ocupado; a cor amarela explica que aguarde um pouco, ou seja que nem entre e nem vá embora; enquanto a cor verde avisa para a pessoa com deficiência auditiva entrar à sala do professor.

Logo, este trabalho teve como propósito a elaboração de um produto de proteção destinado a deficientes auditivos com a finalidade de que eles possam ser inclusos à sociedade em que vivem em ambiente acadêmico e empresarial.

\section{Considerações finais}

Na questão da inclusão social e dos direitos das pessoas com deficiência - física, mental ou sensorial - o Brasil tem avançado grandemente na implantação de tecnologias viáveis na tentativa de oferecer melhores condições de inclusão social dessas pessoas na sociedade. Contudo, é perceptível que as tentativas são superficiais e em muitos casos inexistentes.

De acordo com o que foi pesquisado e avaliado no artigo, é notória a eficácia do produto finalizado nos âmbitos propícios à inclusão dos surdos para que eles sintam conforto ao tentar comunicar-se com os respectivos indivíduos dentro de ambientes fechados. Entretanto, é inegável que a caminhada pela acessibilidade é árdua e realizada com passos lentos.

É importante ressaltar que a sociedade contemporânea está vivendo a era da inclusão. No entanto, o que se percebe é que este público ainda vive os transtornos e as dificuldades de se comunicar, visto que a instalação desses meios de interação será capaz de diminuir (mesmo que 
um pouco) a objeção da comunicabilidade entre surdos e não surdos. Logo, o objetivo do presente trabalho foi alcançado com êxito, uma vez que se foi fabricado o produto de proteção para pessoas com deficiência auditiva podendo ser utilizado para atender este público alvo a ser incluso na sociedade em que vive, especialmente no ambiente de ensino ou até mesmo empresarial.

\section{REFERÊNCIAS}

ARDUINO. what is Arduino. Disponível em: < https://www.arduino.cc/en/Guide/Introduction\#>. Acesso em: 01 de fev. de 2020.

ARAÚJO, I. B. Q.; SOUTO, Filipe Vidal; COSTA JUNIOR, A. G. Desenvolvimento de um protótipo de automação predial/residencial utilizando a plataforma de prototipagem eletrônica Arduino. In: Anais: XL Congresso Brasileiro de Educação em Engenharia (Cobenge), Belém, UFPA. 2012.

BROETTO, Tatiana Olivetto Maranhão; DA COSTA, Bárbara Maria; NAPOLITANO, Carlo José. Inclusão e Acessibilidade: O Papel da Comunicação na Efetividade das Políticas Públicas às Pessoas com Deficiência.

CASIANO,victor Paulo.Surdos e seus direitos: os dispositivos da lei 101.436 e do decreto 5.626.Disponível em : Edição № 21 / Maio de 2017 - ISSN 1982-6842 http://editora-araraazul.com.br/site/revista_edicoes.> .Acesso em: 04 dez.2019.

DA COSTA, Simone Erbs; SELL, Fabíola Sucupira Ferreira; BERCKBROCK, Carla Medeiros Diacui. iLibras em busca da acessibilidade comunicacional e inclusão do surdo no uso das tecnologias colaborativas móveis: uma revisão sistemática da literatura. Colóquio LusoBrasileiro de Educação-COLBEDUCA, v. 2, 2017.

EGGERS, Carla; GOEBEL, Márcio Alberto. Princípios de higiene e segurança no trabalho. Revista Expectativa, v. 5, n. 1, 2005.

GRIMM, Todd. User's guide to rapid prototyping. Society of Manufacturing Engineers, 2004.

GALVÃO FILHO, Teófilo Alves. Tecnologia assistiva para uma escola inclusiva: apropriação, demanda e perspectivas. 2009.

GRACIOLA, Ana Rita. Acessibilidade comunicacional: os processos de comunicação na inclusão social de pessoas com deficiência. 2014.

MATTOS, Ubirajara; MÁSCULO, Francisco. Higiene segurança do trabalho. Elsevier Brasil, 2011.

NOSSA CAUSA.A importância da inclusão dos surdos na educação e no mercado de trabalho. Disponível em: < https://nossacausa.com/inclusao-surdos-brasil/>. Acesso em: 31 de jan. de 2020. 
NR-6. Equipamento de proteção individual. Disponível em: < http://www.guiatrabalhista.com.br/legislacao/nr/nr6.htm>. Acesso em 01 de fev. de 2020.

OLIVEIRA, Victor Hugo Mazon de; SERRA, Sheyla Mara Baptista. Controle de obras por RFID: sistema de monitoramento e controle para equipamentos de segurança no canteiro de obras. Ambiente construído, v. 17, n. 4, p. 61-77, 2017.

RIBEIRO, Rafaella de Oliveira Canquerino; FESTA, Priscila Soares Vidal. ASPECTOS DA COMUNICAÇÃO DO SUJEITO SURDO E A SUA INCLUSÃO NA SOCIEDADE. Memorial TCC Caderno da Graduação, v. 3, n. 1, p. 529-539, 2017.

STROBEL, Karin. História da educação de surdos. Florianópolis: UFSC, 2009.

SOUZA RIBEIRO, Sátila; COUTO PIMENTEL, Susana; GUIMARÃES MIRANDA, Theresinha. Recursos tecnológicos no Ensino Superior: Apropriação e perspectiva do professor surdo. 2018. 


\section{APÊNDICE}

\section{APÊNDICE A -O PROGRAMA UTILIZADO PARA O FUNCIONAMENTO DO DISPOSITIVO DE PROTEÇÃO DE DEFICIENTES AUDITIVOS}

int ledPin $1=11$;

int ledPin2 = 12;

int ledPin $3=10$;

int Botao1 = 2;

int Botao2 = 3;

int Botao3 = 4;

int EstadoBotao1 = 0;

int EstadoBotao2 = 0;

int EstadoBotao3 = 0;

int previous $=\mathrm{LOW}$;

int stateLed $=$ LOW;

long Time $=0$

long Debounce1 = 200;

long Debounce2 = 200;

long Debounce3 = 200;

void $\operatorname{setup}()\{$

// put your setup code here, to run once:

pinMode(ledPin1,OUTPUT);

pinMode(Botao1,INPUT);

pinMode(ledPin2,OUTPUT);

pinMode(Botao2,INPUT);

pinMode(ledPin3,OUTPUT);

pinMode(Botao3,INPUT);

\}

void $\operatorname{loop}()\{$

// put your main code here, to run repeatedly: 


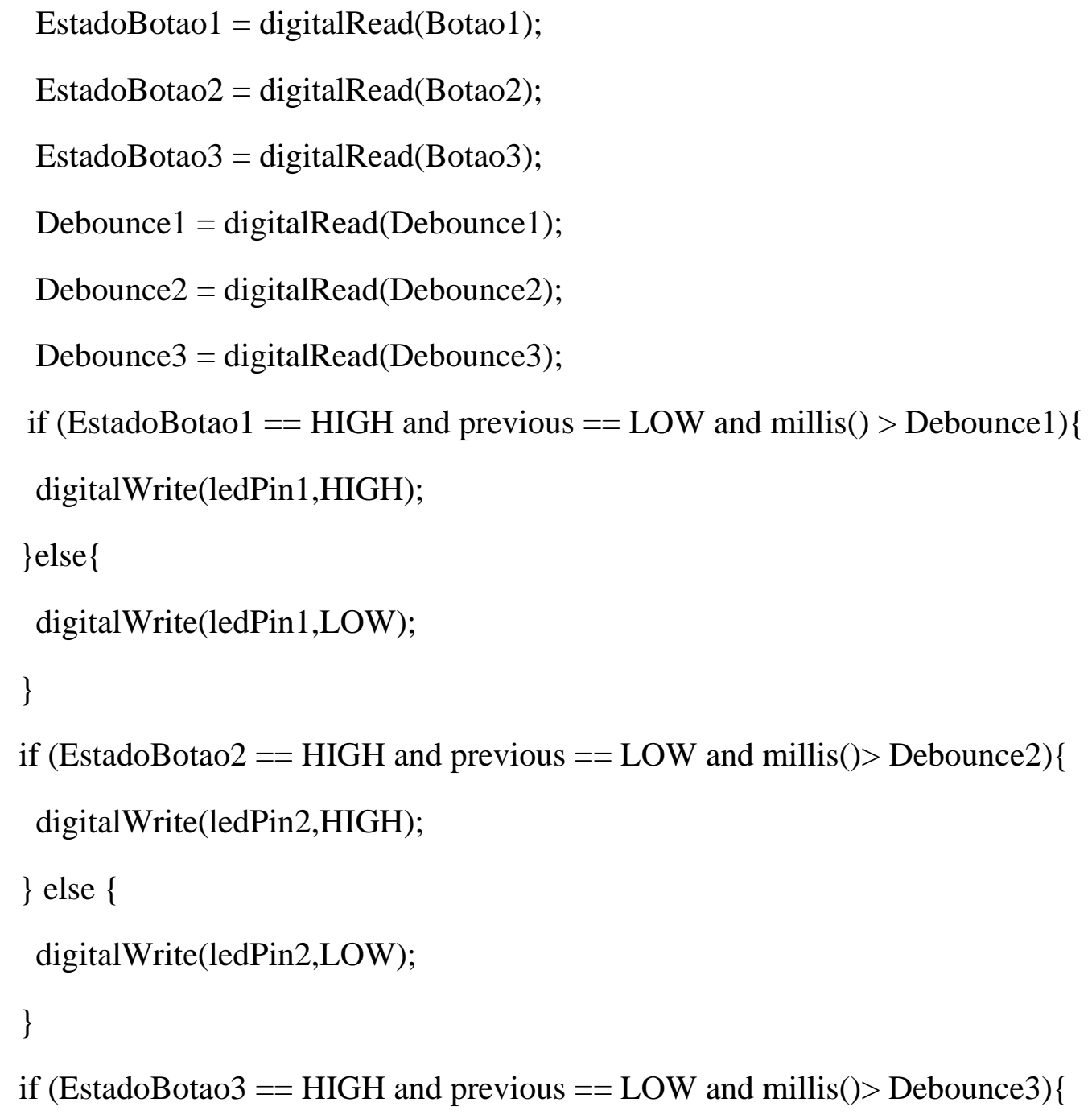

